\title{
A TEM Study of Oxide Scale on U-6Nb
}

\author{
R.M. Dickerson, * P.O. Dickerson, ${ }^{*}$ and R.J. Hanrahan*
}

* MST-6, Materials Science and Technology Division, Los Alamos National Laboratory, PO Box 1663, Los Alamos, NM 87545

Reactive metals, such as uranium alloys, are often used in applications where mechanical and dimensional integrity are important but also are sensitive to environmental corrosion. Previous studies $[1,2]$ have shown that the addition of niobium to uranium enhances its corrosion resistance. Notably, with the addition of $\sim 6 \mathrm{wt} \% \mathrm{Nb}(\mathrm{U}-6 \mathrm{Nb})$, the oxide scale of uranium consists primarily of $\mathrm{UO}_{2}$ and $\mathrm{Nb}_{2} \mathrm{O}_{5}$. It is thought that the $\mathrm{Nb}_{2} \mathrm{O}_{5}$ forms a diffusion barrier and, thus, slows oxidation. What is not known is precisely how and why the $\mathrm{Nb}$ additions enhance the oxidation resistance.

The present work uses transmission electron microscopy (TEM) analyses of focused ion beam (FIB) prepared cross-sections of oxide scales to determine the microstructures of environmentally corroded $\mathrm{U}-6 \mathrm{Nb}$ alloys. Since it is predicted that the $\mathrm{Nb}$ reacts to create an oxygen diffusion barrier, this is a primary focus. These analyses are the first known cross-sectional studies of atmospheric corrosion products on U-6 Nb. Here, two samples, one as-received from storage and one charged with hydrogen, are examined. The techniques and results here will be used in a subsequent study in which we will explore the corrosion mechanisms by relating composition and temperature kinetic effects to the oxide microstructures.

\section{As-Received Material:}

The oxide scale on the as-received samples varies in thickness from $\sim 500 \mathrm{~nm}$ to over $1.5 \mu \mathrm{m}$. It is clearly 2-phase with a dispersion of $\sim 500 \mathrm{~nm}$ unevenly shaped $\mathrm{Nb}$-rich grains within a $\mathrm{UO}_{2}$-majority scale. EDS analyses of the two phases suggest that the Nb-rich phase is relatively oxygen-deficient. Electron diffraction patterns taken from the $\mathrm{Nb}$-rich grains are not consistent with the expected $\mathrm{Nb}_{2} \mathrm{O}_{5}$. More work will be necessary to determine the structure of the Nb-rich phase. A fine 'fanlike' microstructure is observed near the oxide/metal interface (Fig. 2). EDS spectrum image maps of the sample (Fig. 1) clearly show the distributions of $\mathrm{U}$ and $\mathrm{Nb}$ in the scale, an oxygen deficiency in the $\mathrm{Nb}$-rich scale, and a $\mathrm{Nb}$-rich inclusion in the base alloy.

\section{Hydrogen-Charged Material:}

The scale on the hydrogen-charged samples was more homogenous and a more even $\sim 1 \mu \mathrm{m}$ in thickness (Fig. 3). The nanocrystalline, somewhat columnar, microstructure consists of $\mathrm{UO}_{2}$ and $\mathrm{Nb}_{2} \mathrm{O}_{5}$. Composition profiles across the 'columns' revealed no consistent $\mathrm{U} / \mathrm{Nb}$ variation. Any composition variations are likely finer than the $5 \mathrm{~nm}$ probe used or quite irregular and, thus, difficult to reveal.

References

[1] W.L. Manner et al., Appl.. Surf. Sci..,150 (1999) 73.

[2] D. Kelly et al., J. Vac. Sci. Tech., A, 14 (4) (2001) 1959

[3] This research was performed under the University of California contract with the DOE. 

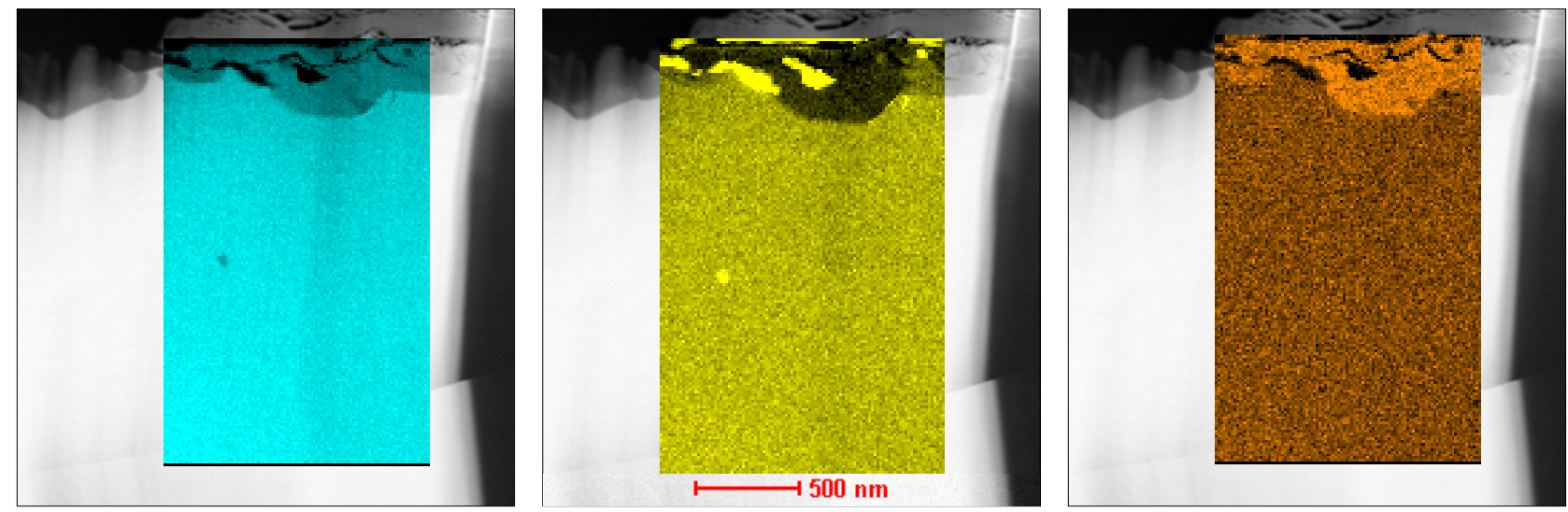

FIG. 1. HAADF STEM Images of the oxide scale of the as-received sample overlaid with XEDS spectrum image maps of $\mathrm{U}$ (left), $\mathrm{Nb}$ (middle), and $\mathrm{O}$ (right).
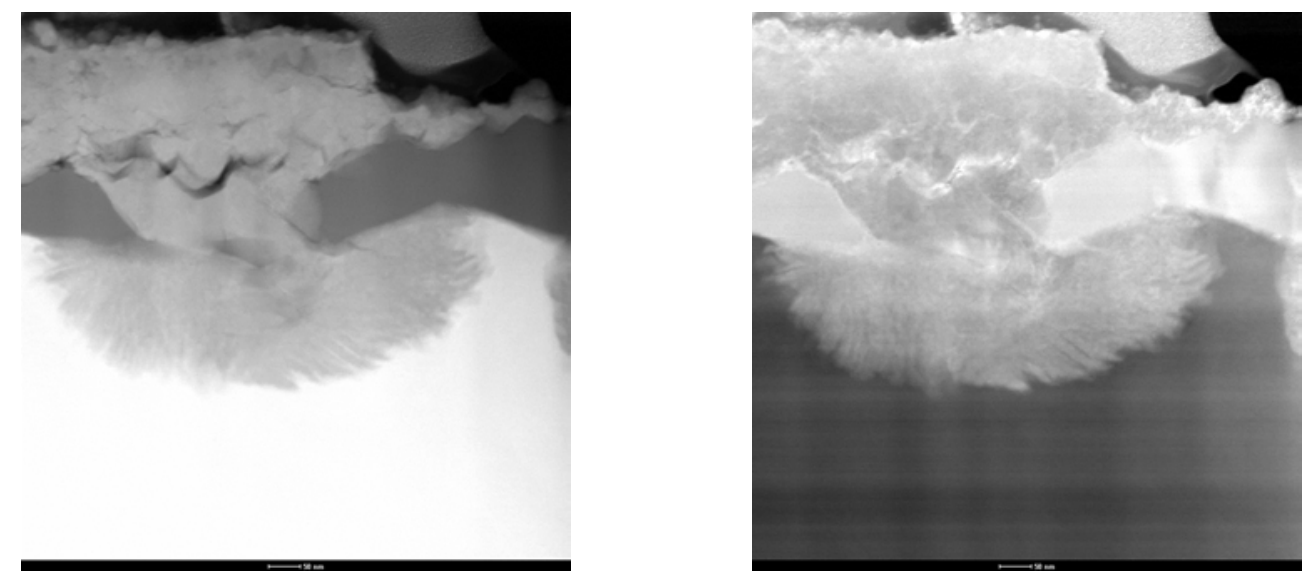

FIG. 2. Comparison of HAADF STEM image (left) and conventional ADF STEM image (right) of the as-received sample. A 'fan-like' structure is observed at the oxide / base metal interface.
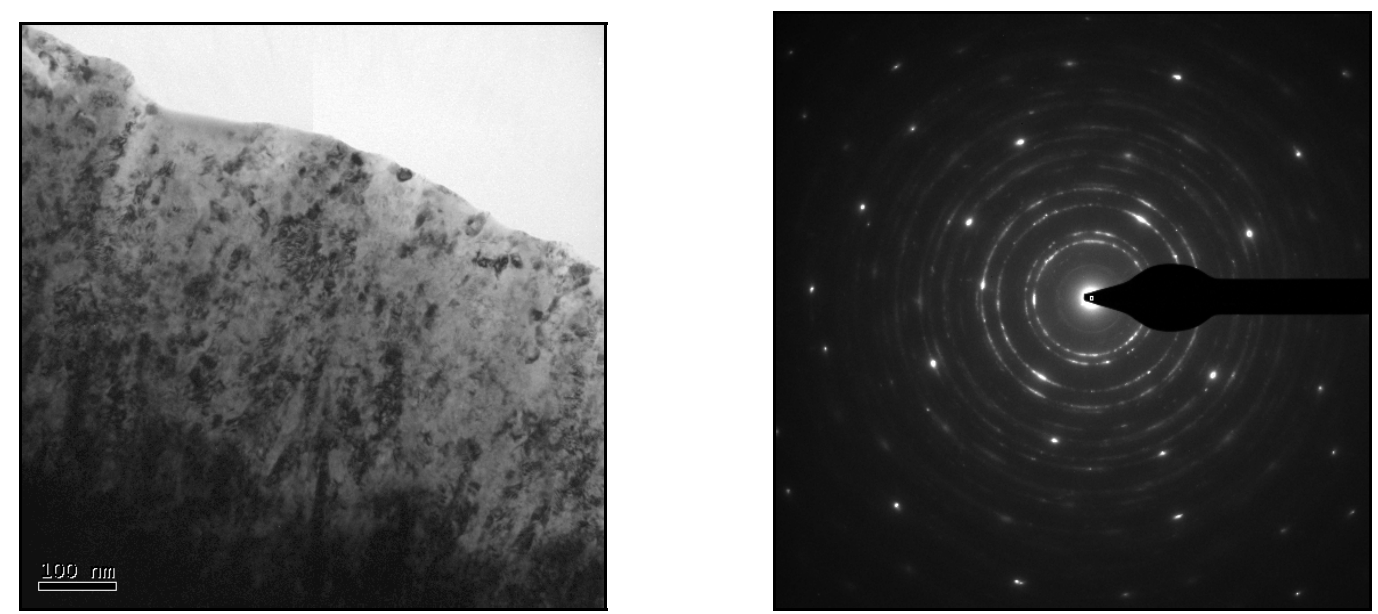

FIG. 3. Conventional BF TEM image (left) of the oxide scale of the $\mathrm{H}_{2}$-charged sample. The oxide scale is nano-crystalline with columnar-appearing structures. A selected area electron diffraction pattern (right) shows broken rings with d-spacing consistent with $\mathrm{UO}_{2}$ and $\mathrm{Nb}_{2} \mathrm{O}_{5}$. 